\title{
CONTENT OF OMEGA-3, OMEGA-6 AND CHOLESTEROL INUF-WHITE SOFT CHEESE CONTAINING VEGETABLE AND MARINE OILS
}

\author{
EL-HAWARY, M.Y. ${ }^{1}$, E. ABDEL-RAFEE ${ }^{2}$, M. A. SALEM ${ }^{1}$ AND
}

SOAD M.H. REFAAT ${ }^{3}$

1. Dairy Science Dep., Faculty of Agr., Tanta University

2. Dairy Technology Dep., Animal Production Research Institute, A.R.C.

3. Egyptian International Center for Agriculture

(Manuscript received 18 December 2008)

\begin{abstract}
UF soft cheese was made either traditionally or by replacing $50 \%$ of the milk fat with olive, sesame or marine oils, replacing $100 \%$ of the milk fat with coconut oil or replacing $75 \%$ of milk fat with corn oil to reach $15 \%$ fat in the final UF milk. Control cheese had the highest content of saturated fatty acids, while marine oil cheese had the lowest. Coconut oil cheese had the highest ratio of mono-unsaturated fatty acids. Corn oil had the highest polyunsaturated fatty acids. Marine oil cheese had the lowest Omega- 6 content, while corn oil cheese had the highest. Corn oil cheese had the highest ratio of Omega-6/Omega-3, while marine oil cheese had the lowest.

Control cheese had the highest cholesterol content and marine oil cheese had the lowest while corn oil, marine oil and coconut oil cheese had very low ratio (LDL/HDL).
\end{abstract}

\section{INTRODUCTION}

The popularity of Domiati cheese in Egypt is well known as being the unique soft cheese type craved by the local consumer. World production of soft cheese is roughly approximates $15 \times 10^{6}$ tones per annum (about $35 \%$ of total milk production) and has increased at an average annual rate of $4 \%$ over the past 30 years (Fox et al., 2000).

Excessive intake of fat in the diet has been linked to certain diseases such as heart disease, cancer, obesity and possibly gallbladder disease and it is associated with high blood cholesterol which increase risk of coronary heart disease.

It has long been recognized that, the amount and nature of ingested fat affect plasma cholesterol concentration, and that high blood cholesterol levels are strongly related to the incidence and risk of atherosclerotic vascular disease, especially coronary heart disease. Several types of evidence including clinical, dietary and drug trails, show that the cholesterol contained in the plasma low-density lipoproteins (LDL) fraction correlated more strongly with coronary heart disease risk than 
do concentration of cholesterol in high density lipoproteins (HDL) (NCR, 1989).

The strongest dietary determinants of blood cholesterol level is the saturated fatty acids content (NCR, 1989). The cholesterol content of the diet has lesser influence. Increased intake of both these nutrients decreases (LDL) receptor activity in liver cells and increases LDL cholesterol level in the blood (Spady and Dietschy, 1988).

The aim of the present work was replacing milk fat totally or partially with vegetable oils or marine oil extract to reduce the contents of soft cheese cholesterol to avoid the risk of consuming milk fat.

\section{MATERIALS AND METHODS}

\section{Materials:-}

Ultrafiltered buffaloe's skim milk (concentration factor $\mathrm{CF}=4$ ) using DDS Lab 20 ultrafiltration unit at $45^{\circ} \mathrm{C}$ with inlet and outlet pressure of 3.6 and 0.6 bar respectively, was obtained from the Unit of Dairy Technology Department, Animal Production Research Institute.

Imported olive oil, coconut oil, corn oil, marine oil extract and locally produced sesame oil were obtained from the local market.

\section{Soft Cheese Making:-}

Skim milk (10\% TS) was ultrafiltered (CF = 4). Milk fat (using fresh cream $60 \%$ fat) or blended with (50\% olive oil, sesame oil or marine oil extracted), $100 \%$ coconut oil or $75 \%$ corn oil, which mixed to give $15 \%$ fat in the final UF milk then homogenized at $65^{\circ} \mathrm{C}$ under pressure of $200 \mathrm{~kg} / \mathrm{cm}^{2}$ using a Rannie homogenizer (Rannie, Copenhagen, Denmark). The homogenized concentrated milk was cooled to $40^{\circ} \mathrm{C}$, salt was added at the rate of $5 \%$, and rennet (Rennilas, Denmark) at the rate of $3 \mathrm{~g} / 100 \mathrm{~kg}$ distributed in $500 \mathrm{ml}$ plastic cans and left to complete coagulation at $40^{\circ} \mathrm{C}$, then sealed and stored at room temperature. Cheese was stored for three months. Samples analyzed were monthly.

\section{Methods of analysis:-}

Cheese samples were chemically analyzed for total solids, fat and total nitrogen contents according to the described method of AOAC (2000).

Titratable acidity was determined according to the method of AOAC (1980). 
The $\mathrm{pH}$ values were estimated using digital HANNA instruments $\mathrm{pH}$ meter Hi 8014-Italy.

\begin{tabular}{|c|c|c|c|c|c|c|c|c|c|c|c|c|c|}
\hline \multirow{2}{*}{ Fresh } & \multirow{2}{*}{ Control } & \multicolumn{3}{|c|}{ Olive oil } & \multicolumn{3}{|c|}{ Sesame oil } & \multicolumn{3}{|c|}{ Corn oil } & \multicolumn{3}{|c|}{ Coconut oil } \\
\hline & & $100 \%$ & $75 \%$ & $50 \%$ & $100 \%$ & $75 \%$ & $50 \%$ & $100 \%$ & $75 \%$ & $50 \%$ & $100 \%$ & $75 \%$ & $50 \%$ \\
\hline TS\% & 38.13 & 38.00 & 38.21 & 38.16 & 38.31 & 38.25 & 38.31 & 38.10 & 38.09 & 38.17 & 38.33 & 38.33 & 38.26 \\
\hline Fat/DM & 40.10 & 39.80 & 39.70 & 39.90 & 40.10 & 40.00 & 40.10 & 93.60 & 39.80 & 39.50 & 40.10 & 40.10 & 40.30 \\
\hline TN/DM & 9.301 & 9.30 & 9.30 & 9.30 & 9.30 & 9.30 & 9.30 & 9.30 & 9.30 & 9.30 & 9.30 & 9.30 & 9.30 \\
\hline Acidity $\%$ & 0.14 & 0.15 & 0.15 & 0.14 & 0.15 & 0.14 & 0.13 & 0.17 & 0.16 & 0.16 & 0.15 & 0.15 & 0.15 \\
\hline $\mathrm{pH}$ value & 6.8 & 6.8 & 6.8 & 6.8 & 6.8 & 6.8 & 6.8 & 6.7 & 6.7 & 6.7 & 6.8 & 6.8 & 6.8 \\
\hline T.V.F.A* & 11.33 & 12.68 & 12.54 & 12.22 & 13.78 & 13.62 & 13.41 & 9.71 & 9.91 & 10.51 & 11.11 & 11.21 & 11.25 \\
\hline
\end{tabular}


Total volatile fatty acids (TVFA) were determined using the method of Kosikowski (1971).

Fatty acid content was determined by Gas liquid chromatography (GLC) according to De Man (1964).

\section{Analysis of Lipids:- \\ Extraction of fat:}

Ten grams of cheese sample were mixed with $7 \mathrm{ml}$ of distilled water, and $\mathrm{pH}$ was adjusted to 1.5 with $0.5 \mathrm{ml}$ of $\mathrm{IH}_{2} \mathrm{SO}_{4}$. The cheese sample was mixed well with $15 \mathrm{ml}$ of ice cold ether, in a blender for $3 \mathrm{~min}$. The mixture was centrifuged at $3000 \mathrm{G}$ for $5 \mathrm{~min}$., and the upper layer was transferred to a bottle containing $\mathrm{Ag}$ of an hydrous $\mathrm{Na}_{2} \mathrm{SO}_{4}$ mixed and left for $5 \mathrm{~min}$. The ether layer was transferred in a screw capped bottle for further analysis (Ramos et al., 1988).

Total cholesterol-concentrations were determined using the reactional kits of CIHL : CHOD - PAP method. $45 \mathrm{ml}$ of cheese oil placed in the ultracentrifuge tube was overlaid with $0.5 \mathrm{ml}$. Of $\mathrm{d}=1.0063 \mathrm{~g} / \mathrm{ml}$. Density solution and then ultracentrifuged using (L5-50 B model Beckman ultracentrifuge, Beckman Instruments, Inc., California, USA, SW 50 rotor, 20 hr, 250 000g. 160oC) Havel et al., 1955). The VLDL fraction was obtained from $1.5 \mathrm{ml}$. Of the top. The pellet was resuspended with the remaining supernatent, and $250 \mathrm{ml}$ of the suspension was mixed with $25 \mathrm{M}$ of the Boehringer reagent $(0.55 \mathrm{~m} \mathrm{~mol} / \mathrm{L}$ phosphotungstic acid and $25 \mathrm{~m} \mathrm{~mol} / \mathrm{LMgcl}_{2}$ ) to precipitate LDL (Guesnet et al., 1988). The HDL fraction was obtained from the supernatant of the centrifugation at $400 \mathrm{rpm}$ for 30 minutes. The LDL fraction corresponded to the pellet resuspended in $0.5 \mathrm{ml}$. Of sodium bicarbonate at $100 \mathrm{~g} / \mathrm{L}$. CHL in the different lipoprotein fractions was measured by the same colourimetric method used for total $\mathrm{CHL}$ determination. Extinction coefficient of $\mathrm{CHL}$ in VLDL, HDL and LDL were 6.05, 5.67 and 1.62 respectively.

\section{RESULTS AND DISCUSSION}

\section{Fatty acids content :}

The variation of fatty acids content between cheese samples as affected by using vegetable or marine oils during storage is shown in Table (1).

In general, it was obvious that almost saturated fatty acids increased during storage period. It was clear that the short chain saturated fatty acids caprillic $\left(\mathrm{C}_{8}\right)$ and the long chain saturated fatty acids stearic $\left(\mathrm{C}_{18}\right)$ which represented the higher percentage of the estimated saturated fatty acids showed the same as they decreased by replacing milk fat with vegetable oils and increased by advancing storage period. 
While the other obtained saturated fatty acids increased along the storage period up to 2 months then decreased till the end of the storage at 3 months.

Concerning the unsaturated fatty acids it was obvious that oleic acid (C18:1) had the highest ratio compared to the obtained unsaturated fatty acids. Unsaturated fatty acids decreased with advanced storage.

Fatty acids profiles of the cheese are indicated in Table (2). As expected in control cheese, saturated fatty acids while, mono- unsaturated fatty acids exhibited ( 33 to $35 \%$ ) and poly unsaturated fatty acids exhibited (7 to $8 \%$ ) of total fatty acids.

In contrast, fatty acids profile of UF-white soft cheese containing vegetable or marine oils were affected with the type of vegetable oils and marine oil. Saturated fatty acids decreased when vegetable oils or marine oil used compared to control cheese. Also, mono unsaturated and poly unsaturated fatty acids increased in all treatments compared with control cheese. These results are in agreement with those found by Alexandrine (2000), Brown et al. (1976) and During et al. (2000) who mentioned that, replacing milk fat with vegetable oils reduced saturated fatty acids and increased unsaturated fatty acids in ripened soft cheese.

Marine oil had the lowest saturated fatty acids. Coconut oil had the highest mono unsaturated fatty acids and corn oil had the highest polyunsaturated fatty acids. These results are in according to the finding of ADA (2003).

Both Omega- 3 and Omega- 6 polyunsaturated fatty acids series are recognized as essential fatty acids because they are not synthesized by the body and must be obtained through diet or supplementation (Maggie and Covington, 2004).

The content of Omega-3 ( $\omega-3)$ and Omega- $6(\omega-6)$ of UF-white soft cheese containing vegetable or marine oils are shown in Table (3).

It is clear from the data that control cheese had low contents of $\omega-6$ and $\omega-3$ this may be due to the control cheese which had high ratio of saturated fatty acids. Alexandrine (2000) mentioned that, fatty acids profile common to dairy products: $17 \%$ saturated fatty acids, $23 \%$ mono-unsaturated fatty acids and $3 \%$ polyunsaturated fatty acids, which include $\omega-3$ and $\omega-6$.

Also, the data showed that cheese containing corn oil had the highest content of $\omega-6$ compared to the other treatments, while marine oil cheese contained the lowest content of Omega- 6 and the highest content of Omega-3 compared to the other treatments. These results are in agreement with those reported by KrisElherton et al. (2000) who mentioned that corn oil contained high level of Omega-6 compared to the other vegetable oils. Also, US-FDA (2005) indicated that marine oil characterized with high content of Omega-3. 
CONTENT OF OMEGA-3, OMEGA-6 AND CHOLESTEROL INUF-WHITE SOFT CHEESE CONTAINING VEGETABLE AND MARINE OILS

T 
Table (3) showed the ratio of Omega- 6 to Omega- 3 which was very low in case of marine oil followed by olive oil, while the highest ratio was in case of corn oil followed by coconut oil compared to the other treatments.

Appel et al. (1993) and Ponnioh (2006) studied, the use of Essential fatty acids (EFAs) to make two classes of hormones - the prostaglandins. The two classes have opposed. Prostaglandins derived from Omega- 6 EFAs stimulate the functions of cells, while prostagnaldinds derived from Omega-3 EFAs reduce their activity. This applies particularly to the cells of the immune to the cells responsible of coagulation. Prostaglandins derived from Omega-6 EFAs stimulated the immune system and help forming blood clots. Prostaglandins derived from Omega-3 EFAs down regulate an immune response, and maintain blood fluidity. Also, Maggie and Covington (2004) mentioned that the American diet contains much more Omega6 EFAs than Omega-3 EFAs. In the American diet, the Omega- 6 EFAs to Omega-3 EFAs ratio is round 2 to 1 . Which is to say there is about 12 times more Omega-6 EFAs in the diet than Omega-3 EFAs. In Australia the ratio is 18 to 1 . A good diet should contain only twice as much Omega-6 EFAs than Omega-3 EFAs. The proportion of 2 to 1 is the ideal ratio recommended. The actual Omega- 6 EFAs to Omega-3 EFAs imbalance in the American diet-contribute to many health deteriorations. The Omega- 6 EFAs to Omega-3 EFAs imbalance exaggerates immune response and blood coagulation.

\section{Cholesterol Content:}

Cholesterol content of UF-white soft cheese containing vegetable or marine oils during storage period are shown in Table (4).

It is cleared from the data that control cheese had the highest amount of cholesterol compared to the other treatments that may be due to the high content of saturated fatty acids in milk fat. These results are in agreement with the findings of John et al. (2001) who showed that, the plasma LDL-cholesterol level increases under circumstances where cholesterol or saturated fatty acids are present in the diet which decreasing the level of dietary cholesterol or substituting unsaturated fatty acids for the more saturated ones leads to a decrease in the circulating cholesterol level.

Marine oil cheese had the lowest cholesterol content followed by corn oil, coconut oil, sesame oil and olive oil respectively. Berner (1993) mentioned that the risk of coronary heart disease (CHD) has been attributed to the high content in cholesterol ( $\mathrm{CHL}$ ) and saturated fatty acids (SFA) of dairy products. Indeed, these nutrients ( $\mathrm{CHL}$ and SFA) were clearly associated with high blood $\mathrm{CHL}$ concentration, atherosclerosis and CHD in humans. As a consequence, nutritionists have emphasized a reduction of animal fats (rich in CHL and SFA), particularly butter fat, as well as an increase of vegetable fats (rich in phytosterols an unsaturated fatty acids) in the daily food intake. 
CONTENT OF OMEGA-3, OMEGA-6 AND CHOLESTEROL INUF-WHITE SOFT CHEESE CONTAINING VEGETABLE AND MARINE OILS 
Low density lipoprotein (LDL) cholesterol and very low density lipoprotein (VLDL) cholesterol the more effective on the cholesterol level blood correlated more strongly with coronary heart disease risk than do concentration of cholesterol in high density lipoproteins (HDL) (NRC, 1989 and Alexnandrine 2000). The strongest dietary determinant of blood cholesterol level is the saturated fatty acids content (NRC, 1989). Increase intake of saturated fatty acids and LDL cholesterol from dairy products decrease LDL receptor activity in liver cells and increases LDL cholesterol level in the blood (Spady and Dietschy, 1988).

From the same Table (4) it could be seen that the ratio of LDL/HDL in case of control cheese was the highest compared to the other treatments. UF-soft cheese containing marine oil was the lowest followed by those containing coconut oil, olive oil, and sesame oil.

\section{REFERENCES}

1. Alexandrine, D. 2000. Effects on cholesterol balance and LDL cholesterol in the rat of a soft-ripened cheese containing vegetable oils. J. of the American College of Nutrition. Vol. 19, No. 4, 458-466.

2. American Dietetic Association (ADA), 2003. Vegetable diets. Can. J. Diet Pract Res. 64(2): 62-81.

3. AOAC 1980. "Official Method of Analysis". Vol. II $14^{\text {th }}$ Ed. AOAC, Arlington, VA.

4. AOAC 2000. Official Method of Analysis. 25 $5^{\text {th }}$ Ed. Washington, USA, 1553.

5. Appel, L.I., E.R. Miller and P.K. Whelton. 1993. Does supplementation of diet with "fish oil" reduce blood pressure? A meta-analysis of controlled clinical trials. Arch Inten Med. 153: 1429-1438.

6. Berner, I.A. 1993. Roundtable discussion on milk fat, dairy foods, and coronary heart disease risk. J. Nutr. 123: 1175-1184.

7. Brown, H.B., V.G. deWolfe, H.K. Natio and D.L. Palmquist. 1976. Polyunsaturated meat and dairy products in fat modified food patterns for hyperlipidemia. J. Am. Diet Assoc. 69: 235-242.

8. De-Man, J.M. 1964. "Determination of fatty acid composition milk fat by dual column temperature programmed gas liquid chromatography". J. Dairy Sci., 10:177.

9. During, A., S. Mazette, N. Comboe and B. Entressangles. 2000. Lipolysis and oxidative stability of soft-ripened cheese containing vegetable oils. J. Dairy Res. In press. 
10. Fox, P.F., T.P. Guinee, T.M. Cogan and P.L.H. Mc Sweeney. 2000. Cheese historical aspects. In fundamental of cheese science. (P.F. Fox, Pudija, P.D. Eds.). Aspen Publishers Press, Maeyland. Pp. 1-7.

11. Guesnet, P., G. Pascal and G. Durand. 1988. Compared effects of different dietary fatty acids on the induced hypercholerohnia in the rat. Cahier de Nutrition et Dieteteique 23: 261-273.

12. Havel, R.J., H.A. Eder and J.H. Bragdon. 1955. The distribution and chemical composition of ultracentrfugation separated lipoproteins in human serum. J. Clin. Invest 34: 1345-1353.

13. John, M.D., A. Laura and K.S. David. 2001. The interaction of dietary cholesterol and specific fatty acids in the regulation of LDL receptor activity and plasma LDLcholesterol concentration. Annals of the New York Academy of Science 11-26.

14. Kosikowski, F.V. 1971. Cheese and Fermented Milk Foods. $2^{\text {nd }}$ Ed. Publ. By F.V. Kosikowski and Assoc. Brook Tondal. New York, USA, 572-574.

15. Kris-Etherton, P.M., D.S. Taylor and P. Huth. 2000. Polyunsaturated fatty acids in the food chain in the United States. Am. J. Clin. Nutr. 71: (1) 795-885.

16. Maggie, B. and M.D. Covington. 2004. Omega-3 fatty acids. American Family Physician. 70 (1): 132-140.

17. NRC (National Research Council), 1989. Diet and Health: Implication for reducing disease risk. Report of the committee on diet and health, Food and Nutrition Board. National Academy Press, Washington D.C. P. 750.

18. Ponniah, R. 2006. Health and nutritional aspects of coconut oil. Asian and Pacific Coconut Community. Jakarta, Indonesia: 1-7.

19. Spady, D.K. and J.M. Dietsch. 1988. Interaction of dietary cholesterol and triglycerides in the regulation of hepatic low density lipoprotein transport in the hamster. J. Clin. Invest. 18: 300-309.

20. U.S. Food and Drug Administration. 2005. What you need to know about Omega3 in fish and shellfish oil. FDA/CFSAN Consumer Advisory. EPA-823. 
محتوى الجبن الأبيض الطري المصنع من اللبن المركز

بالترشيح الاقيق والمحتوي على الزيوت النباتية

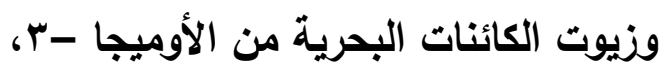

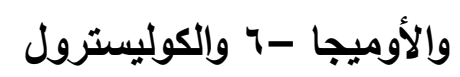

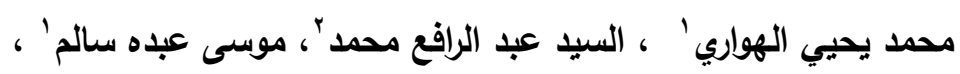

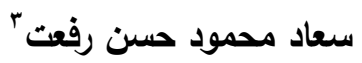

ا قسم علوم الأغنية - ألبان - كلية الزراعة - جامعة طنطا

r قسم تكنولوجيا الألبان - معهد بحوث الإنتاج الحيواني - مركز البحوث الزراعية r المركز المصري الدولي للزراعة

تم صناعة الجبن الأبيض الطري باستخدام اللبن المركز بالترشيح الدقيق (الكونترول) وتم

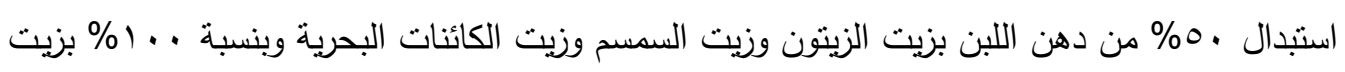

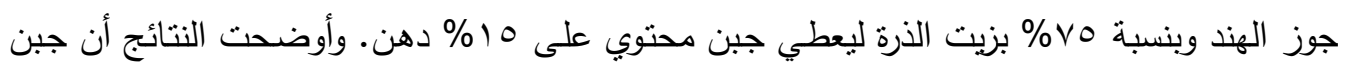

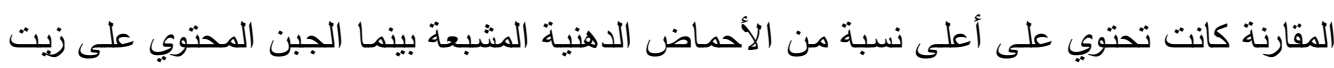

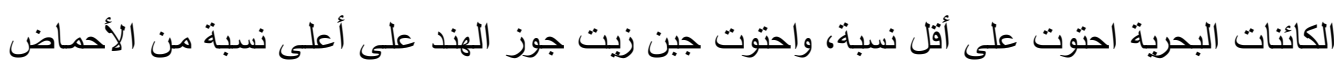

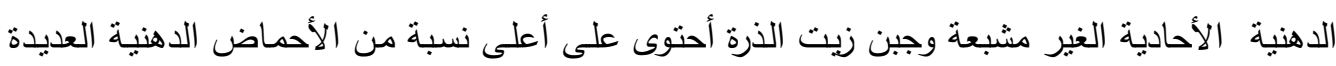

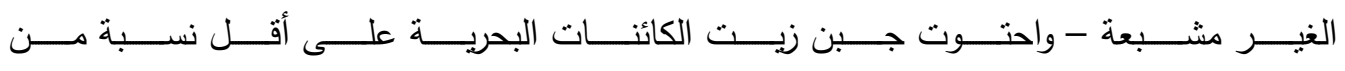
الأوميجا-7 بينما جبن زيت الذرة احتوى على أعلى نسبة وجبن زيت الذرة احتوى على أعلى معدل من الند

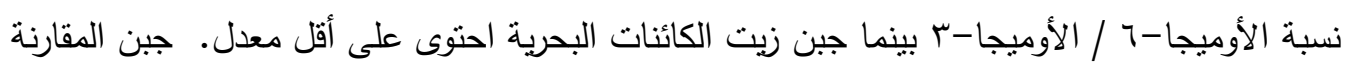

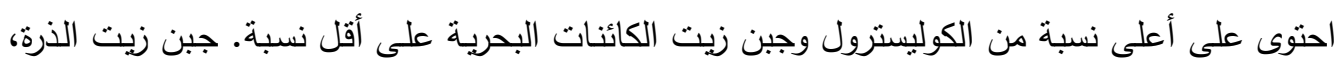

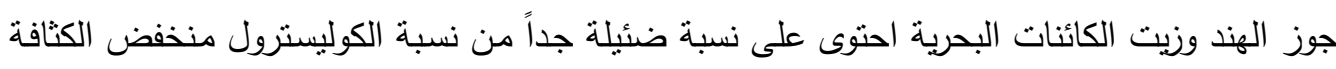
إلى الكوليسترول مرتفع الكثافة. 